\title{
A EMERGÊNCIA DA CULTURA VISUAL: ALGUNS ELEMENTOS DA MUTAÇÃO DO SUJEITO ARTE-EDUCATIVO
}

\author{
FERNANDO LUIZ ZANETTI ${ }^{1}$ \\ ORCID: https://orcid.org/0000-0002-4529-8774
}

\begin{abstract}
RESUMO: O presente artigo é parte de uma pesquisa que problematiza o encontro da arte com a educação no Brasil, nas últimas duas décadas. Pautados em procedimentos analíticos advindos do pensamento de Michel Foucault, buscaram-se delinear as condições de possibilidade da transição de um sujeito que possui, de acordo com Ana Mae Barbosa, proveniência em práticas como a do Canto Orfeônico, para um sujeito forjado na Cultura Visual. Trabalhou-se com uma extensa gama de artigos de revistas acadêmicas, as quais permitiram mapear um arquivo em que tais práticas se instituíram. Notouse que tal transição, apesar de visar a um projeto emancipatório de mudança social, comunga absolutamente com os recentes modelos de controle social dos sujeitos da educação.
\end{abstract}

Palavras-chave: Arte-educação, Filosofia da educação, Pedagogização, Educação da cultura visual, Canto orfeônico.

\section{THE EMERGENCE OF VISUAL CULTURE: SOME ELEMENTS OF THE MUTATION OF THE ART- EDUCATIONAL SUBJECT}

\begin{abstract}
This article is a branch of a research that problematizes the encounter of art with education in Brazil in the last two decades. Based on analytical procedures from Michel Foucault's thought, we sought to delineate the conditions for the possibility of the transition from a subject established, according to Ana Mae Barbosa, in practices such as that of the Orpheonic Singing to a subject forged in Visual Culture. We worked with an extensive range of academic journal articles, which allowed us to map an archive in which such practices were instituted. Despite aiming at an emancipatory project of social change, we perceived that such a transition is absolutely paired with the recent models of social control of the subjects of education.
\end{abstract}

Keywords: Art-education, Philosophy of education, Pedagogization, Education of visual culture, Orpheonic Singing.

\section{LA EMERGENCIA DE LA CULTURA VISUAL: ALGUNOS ELEMENTOS DE LA MUTACIÓN DEL SUJETO ARTE-EDUCATIVO}

\footnotetext{
${ }^{1}$ Universidade do Estado de Minas Gerais (UEMG). Frutal, MG, Brasil. <fernandozanetti@hotmail.com>
} 
RESUMEN: El presente artículo hace parte de una investigación que problematiza el encuentro del arte con la educación, en Brasil, en las dos últimas décadas. Pautados en procedimientos analíticos advenidos del pensamiento de Michel Foucault, se buscó delinear las condiciones de transición de un sujeto que tiene, de acuerdo con Ana Mae Barbosa, proveniencia en prácticas como la del Canto Orfeónico, para un sujeto forjado en la Cultura Visual. Se trabajó con una extensa gama de artículos de revistas académicas, las cuales permitieron mapear un archivo en que tales prácticas se instituyeron. Se notó que tal transición, aunque vise un proyecto de modificación social, comulga absolutamente con los recientes modelos de control social de los sujetos de la educación.

Palabras clave: Arte-educación, Filosofía de la educación, Pedagogización, Educación de la cultura visual, Canto Orfeónico.

\section{INTRODUÇÃO}

O presente artigo visa a tornar públicos alguns resultados de uma investigação que objetivou apreender certos efeitos do encontro da arte com a educação no Brasil, no período de 1995 a 2013. Buscou-se realizar uma descrição do dispositivo de pedagogização da arte, inspirada na genealogia ou na arqueogenealogia de um dispositivo, na acepção foucaultiana, que informasse as práticas artísticas com objetivos pedagógicos, conjugando os campos da educação, da psicologia e da arte.

Assim, na qualidade de um estudo em Psicologia Social, almejou-se problematizar determinados lugares ocupados pela arte, em nossa atualidade, e, mais especificamente, os processos de subjetivação correntes no campo educacional que tomam as práticas da arte como seu instrumento e/ou princípio de ação. Procurou-se, enfim, trazer à baila o sistema de enunciabilidade e o tipo de racionalidade os quais facultam a alguns discursos educacionais existirem em detrimento de outros, ou como se postulam e valoram as relações da arte com as práticas educacionais, através da absorção das práticas artísticas por aquilo que Michel Foucault designou como governamentalidade. Para tanto, tomou-se como referencial teórico a crítica empreendida por Foucault acerca da produção de práticas sociais que subjetivam os indivíduos em torno de certos dispositivos, com vistas ao controle produtivo das condições de vida das populações.

A fim de cumprir tal tarefa, um arquivo de fontes empíricas foi constituído e analisado. A noção de arquivo, neste trabalho, afilia-se às teorizações de Michel Foucault (1979). O arquivo em questão conjuga os dois campos da produção intelectual brasileira anteriormente aludidos: a arte e a educação. Para constituí-lo, elegeu-se um conjunto de artigos veiculados em 19 periódicos brasileiros, dez da área da educação e nove da área de arte, classificados como A1 e A2, no período entre 1995 e 2018, com cerca de 7200 textos.

Tais periódicos são os seguintes: da área de educação - Cadernos Cedes, Cadernos de Pesquisa, Educação \& Realidade, Educaşão \& Sociedade, Educação e Pesquisa, Educação em Revista, Educação Temática Digital, Educar em Revista, Pró-Posições, Revista Brasileira de Educação. Da área de artes: Ars, ArtCultura, Percevejo, Porto Arte, Visualidades, Revista - ABEM - Associação Brasileira de Educação Musical, Revista Brasileira de Estudos da Presença, Urdimento, Sala Preta.

Desse universo, foram selecionados 410 artigos, com base nos seguintes critérios: textos em periódicos da área de educação que tangenciavam temática relacionada à arte e textos de revistas de arte que tratassem de temas ligados à educação. Para analisar cada artigo, o seguinte crivo organizativo foi eleito: ano; área/subárea; assunto; função da arte e do ensino da arte; características da arte e do ensino da arte; deslocamento; problematização ou plano geral do texto.

Por meio de tais categorias gerais, foi possível descrever as linhas fundamentais do referido arquivo; deslindar seus movimentos de avanço e recuo, em relação a determinado assunto, função ou característica; localizar algumas das posições em que os pesquisadores se encontravam e, muitas vezes, visualizar seus estandartes. Todavia, um dos resultados mais fecundos da pesquisa remeteu às repetições e aos deslocamentos que se apresentam como mudanças de direção, abandono, contraposição a uma determinada ideia ou prática anteriormente desenvolvida entre os textos, permitindo compor um traçado 
das linhas argumentativas operadas pelos diversos pesquisadores e, principalmente, das problematizações que eles se propuseram. É importante também ressaltar que adotamos um procedimento de análise e escrita que chamamos de disparador ${ }^{2}$. Os disparadores seriam momentos específicos extraídos do arquivo e utilizados de maneira tática como recurso de escrita e argumentação apresentando de forma muito nítida o jogo de contraste que se quer marcar.

Além disso, foi possível circundar as problematizações propostas pelos autores. Nesse tipo de orientação, nossa tarefa deve ser não somente descrever esses processos, mas também atuar no entremeio da problematização. $O$ que fizemos, neste trabalho, foi a problematização das problematizações em torno de uma das noções que Michel Foucault sugere para atividade analítica, ou seja, "[...] definir as condições nas quais o ser humano 'problematiza' o que ele é, o que faz e o mundo em que vive" (FOUCAULT, 2012, p.193) e, desse modo, "[...] analisar não os comportamentos nem as ideias, não as sociedades nem suas 'ideologias', mas sim as problematizações através das quais o ser se apresenta como podendo e devendo ser pensado, e as práticas a partir das quais elas se formam" (p.194, grifos do autor).

É importante ressaltar também que não pesquisamos como cada área ou subárea da arte ou modalidades artísticas (teatro, dança, artes plásticas, música etc.) se relaciona com a pedagogização, mas entendemos como se comportam as intencionalidades pedagógicas, independentemente da prática específica. O modo de se relacionar com processo de pedagogização é claramente variável, tanto no interior de uma mesma modalidade artística como entre modalidades diferentes. Além disso, existem não apenas autores que ficam restritos a suas áreas de atuação, como também autores que circulam por diversas modalidades ou que não falam a partir de nenhuma modalidade artística, mas a partir da estética, da teoria da arte, da história da arte, da arte-educação ${ }^{3}$ etc. Dessa forma, seria inócuo, para responder aos objetivos deste trabalho, separar as análises por modalidades.

Desse modo, tratou-se de analisar criticamente um dispositivo que, no atual momento histórico do país, disporia a arte - ou determinados atributos e ações acoplados a ela, por diferentes práticas sociais - como um destacado princípio governamentalizador.

Tal princípio seria operado por intermédio daquilo que chamamos de práticas de pedagogização da arte. Concebemos como pedagogização a disseminação de enunciados oriundos de determinados campos do conhecimento (arte, filosofia, ciência etc.) para outros domínios da vida humana, com o intuito de melhorar o homem ou educá-lo, de acordo com os imperativos da agenda social, econômica e política da época.

Ana Mae Barbosa (1990/2008a, p.4), em um texto dedicado à história da arte-educação, afirma que, após o Estado Novo (1937-1945), tem-se o início da pedagogizaçãa da arte na Escola. Esse processo é caracterizado pela autora da seguinte maneira: 1- as práticas artísticas não refletiriam a "especificidade da arte"; 2- os usos das práticas da arte na escola se efetuam de forma "instrumental para treinar olho e a visão"; 3- havia usos das práticas artísticas como liberação de uma função psíquica emocional; 4- buscava-se, com a utilização das práticas artísticas, o "desenvolvimento da originalidade vanguardista e da criatividade entendidas como beleza ou novidade". Nessa abordagem, as atividades em sala se caracterizam pela retomada do desenho geométrico, pelo aprendizado do desenho pedagógico e pela cópia de estampas usadas em outras disciplinas.

Segundo um conjunto de obras de Barbosa (1978/2010b, 1982, 1991/1994, 1998, 1990/2008a) a arte-educação no Brasil passaria por diferentes momentos e rupturas históricas, pela emergência de novas práticas e saberes, que se somam ou se influenciam, ou que convivem paralelamente:

\footnotetext{
${ }^{2}$ Esse procedimento é muito utilizado por Foucault, ao longo de sua obra. Temos, como exemplo, os relatos de um suplício e, depois, de utilização exaustiva do tempo, nas páginas iniciais de Vigiar e Punir. (2013)

${ }^{3}$ Ao longo do século XX e início do século XXI, o ensino da arte passou por uma grande variação de nomes, mostrando um constante processo de avaliação, tanto teórico como prático: educação artística; educação pela arte; arte-educação; arte/educação; ensino da arte; educação visual; Educação da Cultura Visual; educação das práticas estéticas contemporâneas. Neste texto, optaremos pelo termo arte-educação simplesmente por ser o de uso mais frequente, sem com isso querermos nos afiliar ao grupo de teóricos que propõem essa terminologia.
} 
o Ensino ou Pedagogia tradicional, o qual teria suas "raízes" no século XIX, com a vinda de Dom João; o Ensino ou Pedagogia Moderna, sob influência da Escola Nova; o Ensino ou Pedagogia Tecnicista, erigido após o golpe de 1964; e o Ensino ou Pedagogia Pós-moderna, que se desenvolve ao final da ditadura.

Mas efetivamente, neste texto, visamos atualizar uma questão proposta por Barbosa no começo dos anos 1990 em que é trazido à baila o Canto Orfeônico (Estado Novo, 1937-1945) como ponto de emergência (FOUCAULT, 1979) da arte pedagogizada no Brasil.

Uma iluminura desse momento da arte-educação no Brasil indicado por Barbosa pode ser o excerto de um artigo publicado, em 1995, em que o autor discute o entremeio do movimento do Canto Orfeônico e cita Villa Lobos:

Era preciso pôr toda a nossa energia a serviço da Pátria e da coletividade, utilizando a música como um meio de formação e de renovação moral, cívica e artística de um povo. Sentimos que era preciso dirigir o pensamento às crianças e ao povo. E resolvemos iniciar uma campanha pelo ensino popular da música no Brasil, crentes de que hoje o Canto Orfeônico é uma fonte de energia cívica vitalizadora e um poderoso fator educacional [...] Mas para que esse ensino seja proveitoso e venha completar, e não perturbar a evolução natural da criança, é preciso que seja ministrado simultaneamente como os conhecimentos da música nacional. Encarado pois, o problema da educação musical da infância sob esse aspecto, o ensino e a prática do Canto Orfeônico nas escolas impõe-se como uma solução lógica, não só a formação de uma consciência musical, mas também como um fator de civismo e disciplina social e coletiva. (VILLA LOBOS, 1946, p.502-504 apud GOLDENBERG, 1995, p.107).

Se o Canto Orfeônico ilustra de forma efetiva a emergência da arte pedagogizada no Brasil durante o Estado Novo quais poderiam ser as formas de uma arte pedagogizada sete décadas depois? Com tal problematização, gostaríamos de colocar em uma grade de análise crítica (FOUCAULT, 2003) as propostas da Educação da Cultura Visual (ECV) indicada por diversos autores do nosso corpus de análise como a proposta mais recente e avançada da arte-educação no Brasil. Ressalta Dias (2006, p.104):

A educação da cultura visual situa questões, institui problemas e visualiza possibilidades para a educação em geral, características que não encontramos destacadas atualmente em nenhum outro lugar do currículo em arte/educação. Isto ocorre porque ela conduz os sujeitos à consciência crítica e a crítica social como um diálogo preliminar, que conduz à compreensão, e, então, à ação. Nessa análise, a melhor palavra para descrever este processo é "agência": uma consciência crítica que conduz a ações assentadas para resistir a processos de superioridades, hegemonias e dominação nas nossas vidas diárias. Nessa direção, a educação da cultura visual é aberta a novas e diversas formas de conhecimentos, promove o entendimento de meios de opressão dissimulada, rejeita a cultura do Positivismo, aceita a idéia de que os fatos e os valores são indivisíveis e, sobretudo, admite que o conhecimento é socialmente construído e relacionado intrinsecamente ao poder. Necessariamente, a educação da cultura visual incentiva consumidores passivos a tornarem-se produtores ativos da cultura, revelando e resistindo no processo às estruturas hegemônicas dos regimes discursivos da visualidade. ${ }^{4}$

De maneira esquemática, vejamos quais seriam essas problematizações que gravitariam em torno da noção de Cultura Visual: o problema da racionalidade instrumental e sua subjugação do corpo e dos sentimentos (FERREIRA, 2010; PENNA, 2010; SILVEIRA; PEREIRA, 2010); a emergência da noção de interesse do aluno, da importância do contexto, do cotidiano e da voz do aluno (FERRARO, 1999; ARROYO, 2000; CASTILHO, 2001; PENNA, 2002, 2006; LAZZARIN, 2005; MORAES, 2006; CABRAL, 2008; ICLE, 2009; GALIZIA, 2009; RIBAS, 2009; BRITO, 2010; PEREIRA, 2010; POPU, 2012; MARQUES, 2012); o questionamento da heteronormatividade e do machismo, realizado pelas pedagogias feministas e pela teoria queer (STINSON, 1995; SHAPIRO, 1998; MARTINS; TORNINO, 2005; GUIMARÃES, 2005; DIAS, 2006; PINEAU, 2010; RODRIGUES, 2010; CUNHA; SOUZA, 2011); a problematização do autoritarismo sobre a infância (LOPONTE, 2008; SILVA, 2012); a mudança no papel do espectador, primeiro de espectador passivo para intérprete e, depois, para coautor

\footnotetext{
${ }^{4}$ Esse fragmento faz parte de um texto constitutivo do Dossiê de um periódico de arte que apresenta a ECV à comunidade acadêmica brasileira.
} 
(DESGRANGES, 2008; ARROYO; SANTOS, 2009; CRUZEIRO, 2009; NEVES, 2010; POPU, 2012; MARQUES, 2012); as discussões sobre a educação formal e informal e o questionamento da necessidade da escolarização (POPU, 2008; PAIS, 2009; RIBAS, 2009; WAZLAWICK, 2009; SANTOS, 2011); a preocupação em pensar sobre o aluno, não apenas como cidadão, mas como consumidor de imagem, de música etc. (VITELLI, 2009; COELHO, 2009; SEBBEN; SUBTIL, 2010); a criação de uma positividade em relação à Indústria Cultural como instrumento pedagógico (FERRARO, 1999; URIARTE, 2005; PENNA, 2005; ANDRADE, 2009; GALIZIA, 2009); a crítica ao etnocentrismo europeu e o fim da noção de universalismo (OLIVEIRA, 2001; LOPONTE, 2005; BARBOSA; PARDO, 2005; PENNA, 2006; BRANDÃO, 2009; JOLY; JOLY, 2011); a contenda entre o popular e o erudito e entre as belas artes e o artesanato (PENNA, 2005; VICTORIO FILHO, 2008; BRANDÃO, 2009; KEBACH; DUARTE; LEONINI, 2010); e a questão estética do fim da arte (LAZZARIN, 2007; FANTIN, 2009).

Temos em vista dois processos de subjetivação, o do Canto Orfeônico e o do ECV, que expõem dois sujeitos da arte-educação e talvez duas práticas e enunciados educativos. Em breviário, seria possível afirmar ser o primeiro marcado por processos de subjetivação caracterizado pelas práticas e saberes da obediência e sujeição e por conter sua condição de diferenciação limitada pelas linhas traçadas pelo seu grupo social. É um sujeito que buscaria tornar possível a vida em coletivo, via o conceito de humanização enquanto espécie, e teria, como palavras-chave, termos como humanidade, arte erudita ou simplesmente Arte, cidadania, pátria nacional etc.; a Indústria Cultural seria demonizada, por seu caráter alienante e bestializador e, portanto, deveria ser superada pela criação de uma identidade nacional, nos moldes do que se chamaria de uma verdadeira arte.

No segundo estrato, haveria a produção de processos de subjetivação que vislumbrariam estimular a forja de um sujeito capaz de se diferenciar, de se pensar, de se situar no mundo e produzir diferenciações por meio da efetivação da sua autenticidade. Um sujeito que vive em coletividade, via o conceito de humanização, enquanto unidade diferenciada ou que simplesmente afirma a noção de diversidade e do direito a ser diferente. Esse indivíduo não pertence mais àquele coletivo ao qual deveria obedecer, mas é um sujeito que cria, que almeja a mudança, que desafia o poder em nome de uma noção de humano, enquanto individualidades diversificadas, que se autogere e que criaria constantemente novas regras para gestão de si e do mundo. Portanto, o grupo humano apareceria como uma coleção de diversidades e o paradigma multicultural seria tomado como referência. Além disso, esse sujeito teria a imagem e a interpretação da imagem como objeto de trabalho, mais do que a noção de obra, e veria a Indústria Cultural como passível de ser utilizada nas práticas pedagógicas, sem maiores problemas.

Esses dois quadros apresentam dois modos de subjetivação, porém, um mesmo plano de imanência a ser trabalhado: a ação sobre o corpo. De maneira simplificada, as ações que miravam o sujeito do Canto Orfeônico criavam formas diretas de intervenção sobre o corpo, tal qual àquilo que Foucault (2013) chamaria de uma anátomo-política. Nesse sentido, o ensino da arte e suas variações teria uma função disciplinar, visaria à submissão do indivíduo, sua localização como elemento específico no interior de uma população. Já o sujeito circunscrito nas práticas da ECV estaria sob a égide de um si mesmo; seu avivamento, enquanto elemento da população, se faz de forma indireta, por ofertas de modos de vida e estímulos, para que os próprios indivíduos façam variações nesses modos de vida e criem outros. Estaríamos, talvez, no turbilhão daquilo que Foucault tomou como, para além da disciplina, a questão do controle, mas também da ética e do cuidado de si.

Diante de tais conjecturas instou-se refletir sobre as proveniências (Foucault, 1979) desse sujeito da pedagogização. Existiria alguma hereditariedade ou de negação de uma hereditariedade entre o sujeito pedagógico do canto orfeônico e o sujeito da ECV? Apesar da grande variação de formas sofridas pelo ensino nos últimos setenta anos que linhas de forças e saberes permanecem? Uma relação que pudemos notar nas linhas do arquivo dos artigos acadêmicos nos impulsiona a iniciar a reflexão a partir das estratégias de bumanização.

\section{A PEDAGOGIZAÇÃO COMO HUMANIZAÇÃO E SENSIBILIZAÇÃo PARA A DIVERSIDADE E PARA A DIFERENCIAÇÃO}

Ao realizar a análise do corpus, pudemos notar que a questão da humanização pela arte é uma constante. Uma ideia de humanizar é vista por quase todos os autores como redenção para a condição 
humana, como baliza na relação entre os povos e norte para o processo educativo. Nesse contexto, estariam explícitos os esforços e artifícios que os autores faziam, para que a arte e o seu ensino fossem vistos como elemento humanizador. Entretanto, encontramos um texto em nosso corpus que problematiza a bumanização pela arte.

Em 2009, foi publicado em uma revista de artes o texto Da Pedagogia do Ator à Pedagogia Teatral: verdade, urgência, movimento, de autoria de Gilberto Icle. Esse texto é assaz importante, pois é um dos únicos no universo dessa pesquisa em que o autor admoesta, sem concessões ou propostas reparadoras, as pedagogias da arte. O autor censura a Pedagogia Teatral por mudar os objetivos do espetáculo para uma prática social de humanização; discute a promessa da pedagogia teatral de transformar os indivíduos; problematiza a pedagogização da arte, a banalização da improvisação teatral e a emergência do diretor pedagogo; reposiciona a Pedagogia Teatral como verdade construída nos jogos do verdadeiro e do falso; e, por fim, localiza, na passagem da Pedagogia do Ator para a Pedagogia Teatral, o processo onde ocorre essa humanização dos objetivos do espetáculo. Para o autor, se, na Pedagogia do Ator, os objetivos eram de melhorar a eficiência da atuação, no seio do teatro, na Pedagogia Teatral, a intenção será responder à "[...] urgência de humanização dos sujeitos na vida contemporânea." (ICLE, 2009, p.5). Conforme o autor (2009, p.5), a Pedagogia Teatral fez do teatro uma prática social de humanização - e ironiza: "Será mesmo possível 'transformar' indivíduos em cidadãos com algumas poucas horas de prática de improvisação?"

Nesse sentido, de acordo com Icle, seríamos instados a inferir que a humanização foi um dos elementos primevos, nesse processo de pedagogização da arte, onde se torna possível afirmar que, para pedagogizar, é necessário antes humanizar. É importante frisar que essa noção já estava presente, no tempo de Villa-Lobos, como uma prática civilizatória e continuaria até nossos dias, porém, com profundas mudanças em sua constituição.

Outro texto que vale ressaltar é Mutações do sensivel: a arte deslocalizada e o corpo desincorporado, de Cynthia Farina, publicado no ano de 2011, em um periódico de arte. Se o tex to de Icle é o único que põe em questão a noção de bumanização, este será o único a tratar da sensibilização como objeto de problematização.

A autora questiona os paradigmas atuais de corpo e discute o tema da sensibilidade. Apresenta as visões de Jean Claire e Paul Virilio, como ferramenta para pensar sobre a arte abjeta e perversa, e a arte sem lugar. Aponta uma mudança na política do sensivel, na qual arte se converte em pura energia. Uma arte sem corpo, sem encontros, sem experiência estética, sem política e sem lugar, que ataca a moralidade, o racional, os limites do aceitável e tolerável na percepção, e ataca a sensibilidade. Coloca em questão o corpo no que ele tem de frágil, contingente, suscetível e impactante, e expõe a ficção de que são feitas essas formas: a moral, a sensibilidade e a razão de sua configuração. A autora já não alude mais a conceitos, como arte contemporânea ou cultura, mas sim às práticas estéticas contemporâneas. Estas aparecem como uma forma de rompimento com a moralidade e com o ímpeto de salvação do ser humano e o sentimento de humanidade, amplamente defendido nos artigos acadêmicos.

A radicalidade desse texto é rara, em nosso arquivo. A temática da sensibilidade ou sensibilização também está contextualizada em grande número de artigos consultados, mas, em geral, com outro teor ligado à humanização. Esses artigos asseveram que o aperfeiçoamento da pessoa humana depende de processo sensibilizante (BRITO, 2012), que a sensibilidade e a humanização podem construir seres humanos para um pensamento criativo (SITTA; ORMEZZANO; POTRICH, 2005); ou, ainda, que a sensibilidade permite relações mais aguçadas com a alteridade e que é capaz de tornar a moralidade universal mais palatável (HERMANN, 2008).

Portanto, há um abismo entre essas duas abordagens sobre a sensibilidade e a humanização e os outros textos do corpus estudado. O texto de Farina, da mesma forma que o de Icle, ocupa uma raridade no contexto estudado. Devido à proximidade temporal aos nossos dias, podemos ensaiar a possibilidade de estarmos caminhando para o que destaca essa política do sensivel indicada no texto de Farina. Entretanto, a esmagadora maioria dos textos faz coro para a ideia de sensibilidade como humanização. Esta surge como um elemento primordial, no processo de pedagogização da arte, e a sensibilidade funciona como seu complemento. Em nosso contexto, a máxima que representa a maioria dos autores estudados é: para ensinar, é necessário humanizar e, para humanizar, é imprescindível sensibilizar e tornar o indivíduo mais sensível ao mundo. 
De acordo Frayze-Pereira (2003), um dos autores do nosso arquivo, essa noção de sensibilidade que, conforme indicamos, é utilizada pela maioria dos autores, é tributária de uma forma específica do conceito de diferença. Para o autor, do mesmo modo que para Nietzsche (2001) ou Foucault (2014) ou ainda Deleuze (2018), a noção de diferença deveria se referir a uma não-identidade e nunca a uma diversidade. Distinguindo-se tanto desse sentido de diferença apresentado por Frayze-Pereira, quanto da proposta de uma política do sensivel, mencionada acima, a sensibilidade bumanizada constituiria uma administração da diversidade, na lógica da tolerância. Nessa posição, tornar-se sensivel seria aceitar as diferenças do outro enquanto identidade e não como a possibilidade de tornar-se diferente, no contato com o Outro, ou seja, transformar-se a partir da relação com aquilo que não se é, ou ainda, a diferença como processo e não como condição.

Insta-nos também o texto Por uma Crítica à Nova Filosofia da Educação Musical, de Luís Fernando Lazzarin (2008) que, além de estar alinhado a uma posição crítica em relação à pedagogização da arte, lança-nos diretamente na questão, apresentada acima, concernente ao binômio diversidade/diferença. Esse texto põe em exame a noção de multiculturalismo por esta se apresentar como uma administração do convívio com base em estratégias de sedução utilizando táticas mais democráticas e menos etnocêntricas. $O$ autor afirma que, no campo da pedagogia da arte, a multiculturalidade foi naturalizada como resposta a questões de diferença e identidade. Mas, novamente, a diferença aparece aqui como diversidade ou uma coleção de elementos os quais se toleram e são organizados por uma lógica normalizadora essencial. Esses diferentes elementos da cultura seriam vistos como exemplares de identidades culturais puras, ou como "[...] um colorido e feliz patrimônio coletivo." (LAZZARIN, 2008, p.122). De certo modo, a noção de multiculturalismo e diversidade se constituíram em um tipo de prática taxonômica em que os elementos de culturas diferentes devem ser preservados.

Por conseguinte, temos, além do conceito de sensibilização, a ideia de diversidade e diferença. O sensível, no contexto da arte-educação, aplica-se como um elixir que possibilitaria a produção de diversidade.

Cabe ressaltar que, para os dois autores citados acima, apesar da pedagogia multiculturalista promover a boa convivência entre as culturas, através da tolerância, da preservação patrimonial e da prevenção de sua aculturação, esta geraria seu enfraquecimento, pois a ausência de embates culturais entre grupos diferentes criaria uma estagnação pela falta de trocas. O que atravessa o aspecto focalizado por esses autores é uma mudança geral de paradigma, inclusive antropológico. A preservação cultural não seria mais feita com base no isolamento das culturas e da noção de aculturação, mas na subsunção dos limites, no incentivo ao hibridismo, à fluidez, à consideração pelo interesse dos envolvidos e pela valorização das situações particulares. Portanto, haveria um incentivo à diferenciação e produção de novas culturas e o não "congelamento" das culturas existentes.

No entanto, a noção de sensibilidade à diversidade, exposta na quase totalidade dos artigos estudados, ao invés de criar culturas híbridas, fluidas, as quais aceitam o novo e consideram os interesses particulares, acaba tornando o sujeito mais rígido, em uma suposta identidade, porque este não suporta a oposição que pode fazê-lo mudar. No processo de pedagogização, sensibilizar é organizar e respeitar as diferenças, sem o compromisso de se diferenciar ou se afetar. Nesse sentido, a noção de multiculturalismo realizaria uma espécie de pasteurização da vida e das misturas, a qual retira o sofrimento trágico das mudanças, com sua leitura científico-positivista do mundo e do homem (LAZZARIN, 2008). Além disso, essa delimitada noção de sensibilidade promoveria uma espécie de neutralização da formação do aluno, em que ser sensível passaria pelos desenhos estereotipados para colorir, pelas datas comemorativas, pelas receitas fáceis, pela noção de dom e pelo mito da professora criativa (LOPONTE, 2006).

Assim, a pedagogização estabelece relações em que os embates e o possível sofrimento advindo destes devem ser evitados. Essa sensibilidade, ou melhor, a sensibilização é o momento quando se fixaria um contínuo consenso a priori, no qual aquilo que vier pelos sentimentos, pelas emoções, de um interior da pessoa, deve ser respeitado por uma suposta veracidade singular. Nesse aspecto, a arte e suas variações tornam-se o bálsamo desse processo. Então, aqui, sob os auspícios de uma espécie de sensibilidade interiorizada, a arte seria unida a um tipo de psicologia para dar um lugar possível para que a fala de um eu mais profundo do sujeito seja audível. 
Essas práticas artísticas psicologizadas objetivariam o desenvolvimento de características e funções do sujeito delimitadas por paradigmas psicológicos, e não o desenvolvimento da atividade artística, e teriam como autores de referência alguns teóricos tradicionalmente ligados à psicologia e psicanálise (Piaget, Vygotsky, Roger, Dewey, Freud, Jung), e não autores do universo artístico.

Para ilustrar esse modus operandi, tem-se o exemplo de uma autora (OSTETTO, 2009, 2010) que sugere algumas funções psicologizadas para a arte e seu ensino, tais como: levar a sensibilidade para dentro da escola, criar autonomia, humanizar, criar, trilhar o desconhecido, cultivar o ser sensível, promover uma reaproximação da razão com a emoção, integrar as diferenças (no caso, diversidade), restabelecer o equilíbrio, não privilegiar o uso de técnica, mas o espaço da partilha, não buscar habilidades, mas o desejo, o encontro, a troca e o pertencimento a um grupo. Nesse lugar, as práticas da arte assumem um conteúdo ditado por uma psicologia, em que as relações se tornariam didatizadas, com uma intencionalidade psicopedagógica prescrita, perdendo seu possível conteúdo trágico ou catártico e de devir.

O fim do trágico na arte foi discutido por Nietzsche, desde suas primeiras obras. E é sabido que, primeiro, Sócrates e Platão e, depois, Cristo foram imputados pelo autor como os algozes desse modo artístico. Trazemos isso à baila, porque ainda hoje se discute a influência de Platão na relação entre arte e educação. E, mais do que isso, alguns autores creditam à pedagogização da arte uma herança platônica.

Autores do nosso corpus, como Richter ou Rodrigo, põem em suspeição o platonismo, problematizando a polarização que realiza entre útil e inútil, na educação, e a submissão da arte à palavra. E, citando Rancière, salientam que, apesar de hoje não tomarmos mais o "[...] simulacro como oposto da Ideia", ainda "[...] somos possuídos por Platão" (RICHTER, 2005, p.190), de sorte que a educação mataria, por exemplo, na pintura sua imprevisibilidade do encontro dos corpos, a fim de encontrar a verdade perceptiva. Esses autores sustentariam que há uma insubmissão da pintura à palavra e ao mundo, e criticam o platonismo, que relacionaria a sofística, a poesia e a pintura ao campo de falso, ou seja, em que apenas aquilo "[...] que é insipido é verdadeiro belo e bom" (2005, p. 195), quebrando assim o encanto da poesia em favor da utilidade (RODRIGO, 2006). Entretanto, há um autor (BRANDÃO, 2001) de ímpeto conciliativo que reafirma, com base no pensamento platônico, a noção de que a arte precisa da função pedagógica para sua dignidade. Contudo, ao mesmo tempo, assinala que a educação necessita da força da poesia para revelar a verdade (essência, que não imita o real, mas o recria) que nem a filosofia consegue acessar. Dessa maneira, a arte não poderia pretender-se autônoma e nem a educação dispensar os serviços da arte. No entanto, as duas deveriam ter como fim último a formação do cidadão e a construção de uma vida melhor e mais justa.

Apoiados nesses embates, podemos sustentar que a pedagogização da arte implicaria limpar outros efeitos que a arte possa vir a ter, para ressaltar apenas sua função educativa. Retomando o raciocínio de Farina, Loponte e Lazzarin, é possível inferir que hoje esse resquício de platonismo extrai da arte seu phátos arrasador, seu conteúdo violento, nocivo ou radical contra a coletividade ou contra as individualidades.

Essa espécie de platonismo indicou em determinada época para aquele sujeito que havia sido exemplarmente produzido nas práticas do Canto Orfeônico, o projeto de homem e de uma educação que colocava a racionalidade e o propósito coletivo acima do indivíduo. Todavia, o que temos atualmente não é mais esse platonismo em sua forma primordial, pois o fim último da formação do cidadão proposta por esse idealismo sofreu grandes variações. Com a emergência da ECV, o aluno não se apresenta mais só como cidadão a ser formado, porém, como consumidor de imagem, de música, gestos, sensações etc. Temos também o questionamento da racionalidade, por esta subjugar o corpo e os sentimentos, a emergência da noção de interesse do aluno, da importância do contexto, do cotidiano e da "voz do aluno". Ainda há a noção de cidadania, mas esta passa a conviver com a supervalorização dos interesses individuais. Ainda há o senso de utilidade do ensino da arte que passa a não ter mais um sentido e uma razão absolutamente públicos, como em Platão, constituindo efetivamente algo da ordem da vida cotidiana e do foro íntimo do sujeito. As propostas atuais de educação, tematizadas na arte e na cultura, revelam a busca por realizar uma vida coletiva, mas a qual se organiza a partir do indivíduo, ou melhor, 
do sujeito não sujeitado, subjetivado voluntariamente, ou, como diria Foucault, um sujeito livre, ainda que governamentalizado. ${ }^{5}$

Em vista de tais análises, teríamos a seguinte proveniência para o processo de ensino da arte hodierno: para ensinar, é necessário humanizar, sensibilizar para a diversidade e instruir o sujeito sobre como apresentar à coletividade seus interesses e suas idiossincrasias, de maneira simples, inteligível e com urbanidade, sem ferir diretamente a identidade do outro.

\section{A PRODUÇÃO DO SUJEITO DA ECV}

Estamos de acordo que presenciamos a forja de um sujeito que já não é aquele do Canto Orfeônico. Sabemos também que entre aquele sujeito do Estado Novo e o hodierno houve uma série de variações e outros personagens. Contudo, nesse momento, gostaríamos de questionar como um aluno interioriza um modo de gerenciamento de $\mathrm{si}^{6}$, através das práticas como as da ECV? Como se organiza essa proposta? Quais seriam as medidas e procedimentos para a produção desse sujeito?

No intuito de responder a tais questões, vejamos como os autores do corpus explicitam o desenvolver e a atualidade desse processo, em algumas áreas específicas. Há autores (CABRAL, 2008) que problematizam, por meio da história do teatro, os modos de ensino desde o texto memorizado, passando pela livre expressão e chegando hoje a um outro tipo de mediação o qual tem o jogo teatral, o jogo dramático e o drama como novos parâmetros de criação. Essa forma de teatro caracteriza-se pela releitura, fragmentação, abordagem não linear, apropriação dos temas clássicos, mudança constante de perspectiva, interdisciplinaridade, heterogeneidade e interculturalidade. É um ensino que visa a ser capaz de promover as mudanças decorrentes da inseparabilidade das dimensões cultural, pessoal e política, pela ampliação do capital cultural e linguistico associado ao engajamento emocional. Nessa condição, propõemse funções de foro íntimo ou psicológico para a arte e seu ensino, como: olhar para dentro de si mesmo; buscar a aproximação do cotidiano; desenvolver a expressão; desenvolver a função cognitiva no sentido dado aos conhecimentos que o aluno adquire, ao interagir com o texto em cena. Podemos ver essa proposta da pedagogia teatral resumida na fala de Brian Way, um discípulo de Peter Slad (CABRAL, 2008, p.37): "[...] estamos preocupados com o desenvolvimento das pessoas e não do teatro."

Essa ideia se articula com duas questões importantes da pedagogia. Uma dessas é mais antiga e consiste em saber de antemão o que desenvolver no aluno e quais as competências a serem estimuladas com uma determinada atividade. Qual a intencionalidade pedagógica do ato (LIMA, 2006)? A segunda introduz o problema do contexto. Essa noção de contexto, seguida também da ideia de cotidiano, é amplamente explorada por diversos autores, nos periódicos analisados, alguns dos quais partem da antropologia, enquanto outros recorrem à psicologia social. Em um artigo sobre educação musical, a autora baseia-se no saber antropológico, para questionar se os significados diferentes da música, na escola e na comunidade, podem gerar desinteresse dos alunos pela música. Na sequência, pergunta: “O que acontece nesse lugar, nas vidas e nas experiências dos alunos, que irá influenciar minhas abordagens pedagógicas?" (RUSSELL 2006, p. 12). Assim, além da intencionalidade pedagógica do ato, o instrutor ou professor de arte deve conhecer o contexto/cotidiano de vida de seus alunos, de sorte a efetivar um ensino adequado.

No intuito de demostrar alguns movimentos no interior do arquivo e para parametrizar a discussão sobre essa necessidade que se apresenta premente sobre se conhecer o cotidiano, destacamos um texto do corpus de 1996 em que a autora (TROJAN, 1996) trazia à baila a discussão sobre a importância da arte como fonte humanizadora do homem. No interior de um cariz marxista, propõe a

\footnotetext{
${ }^{5}$ De acordo com Agamben (2009, p.46), Foucault “[...] mostrou como, numa sociedade disciplinar, os dispositivos visam, através de uma série de práticas e de discursos, de saberes e de exercícios, à criação de corpos dóceis, mas livres, que assumem a sua identidade e a sua 'liberdade' de sujeitos no próprio processo do seu assujeitamento."

${ }^{6}$ Esboça-se aqui a noção trazida por Costa (2009, p.182) sobre o sujeito educativo forjado na cultura do empreenderismo e no acúmulo de capital cultural. Tais sujeitos são caracterizados como "alguém que aprende sozinho. A iniciativa individual e o processo de aprender a aprender são muito mais enfatizados do que o trabalho em equipe e o ensino, e devem voltar-se, sobretudo, para a inovação." Entra-se na lógica do cada um com seu projeto. De acordo com o autor, "isso concorre para tornar as relações de sociabilidade frágeis, fugazes e movidas pela concorrência e por cálculos racionais frios, haja vista que implicam investimentos." (idem). Isso gera aquilo que Costa chama de "mônadas investidoras" sendo estas incapazes de agenciamentos coletivos e de produzir outros modos de vida que não aqueles inoculados pelo mercado.
} 
arte como não-mercadoria e como superação do útil, criticando sua fetichização pela Indústria Cultural, embora, ao mesmo tempo, sustente que a falta de acesso à arte erudita, a saber, a europeia, faz as pessoas produzirem arte "menos elaborada". Portanto, na tentativa de humanizar o sujeito a ser educado, a autora narra, com base em um registro humanitário, que, em 1996, ainda se mostra etnocêntrico e que deixa entrever uma concepção de arte não europeia como sendo menos elaborada. Atualizado e contrastado com as ideias defendidas pela ECV, o que essa autora sugere é um ensino da arte baseado em cânones europeus e em uma ideia de arte universal. A partir de 2005, ainda haverá alguns registros no mesmo sentido, adotado por essa autora, mas serão absolutamente raros. Ao comparar esses dois últimos textos, notamos que, em uma década, a noção de universalismo da arte perde espaço para a ideia do contexto do aluno e seus correlatos (cotidiano, voz do aluno etc.).

Por conseguinte, desde 1999, teríamos o crescimento de uma pedagogia pautada no cotidiano e no contexto do aluno. Também é salientado que a Arte Contemporânea deslocaria o seu foco do produto para o processo e para a recepção. Isso exigiria do público a reflexão sobre as relações que as produções artísticas estabelecem com a história da arte, com a cultura de massa, com o mercado, com a política e com as tecnologias. Essa reflexão geraria uma certa desnaturalização ou fim da inocência da arte. Tal discussão traz à baila o dito de que não trabalhar a Arte Contemporânea, na escola, é uma atitude política para manter o grande público subordinado ao processo de consagração da produção cultural da atualidade, e que se deveria pensar o ensino da arte de forma menos romantizada, indicando, inclusive, a noção de cotidiano e cultura de massa como caminho para a aproximação com a arte (FERRARO, 1999).

No ano de 2009, temos uma pequena variação na temática do contexto/cotidiano. Com respaldo na abordagem de Paulo Freire, é problematizado o contexto da Educação de Jovens e Adultos no ensino da música. Critica-se o paradigma moderno científico e, com a noção de cotidiano da sociologia de Albion Small, afirma-se que, para educar, não é necessária a experiência escolar e que os espaços, como a comunidade e o cotidiano, podem estruturar a formação do aluno (RIBAS, 2009). A discussão sobre o cotidiano acaba por levar à problematização da própria escolarização, considerando-se a instituição escolar apenas como um dos possíveis locais para essa formação, na sociedade, ao lado da comunidade, da família e das novas tecnologias da informação e comunicação.

Nessa mesma direção, porém, de maneira um pouco menos radical, há o autor Fernando Stanzione Galizia (2009) para quem o ensino da música não deve romper com o cotidiano do aluno, nem desconsiderar as novas tecnologias. Nesse sentido, a Indústria Cultural, por ter uma importante presença nesse cotidiano, deve ser usada pedagogicamente.

A noção de Indústria Cultural, na perspectiva frankfurtiana, é uma temática altamente recorrente entre os autores pesquisados. Ela é utilizada tanto como instrumento para problematizar a arte e suas formas de ensino quanto como objeto de problematização.

Nessa primeira forma de uso, exalta-se a análise de Adorno como guia para a organização do ensino da arte. Tal análise enfatiza funções ligadas à emancipação social, à produção de identidade e à participação na sociedade. E, assim, a arte e seu ensino servirão para dar prazer e para informar e conscientizar, além de, e principalmente, estimular a inteligência, a imaginação e a criatividade das pessoas (BERTONI, 2001). Será igualmente assinalada a face nociva da Indústria Cultural, que, segundo os autores, reforça a marginalidade cultural, afasta o povo de sua cultura, prostitui os valores estéticos (KATER, 2004; LOUREIRO, 2009) e reifica os sujeitos (FABIANO, 2003).

Já como objeto de problematização, enuncia-se a necessidade de se absorver a Indústria Cultural como cultura do aluno (PENNA, 2005), de se pensar a possiblidade da cultura de massa como caminho para a aproximação com a arte (FERRARO, 1999), como uma fonte pedagógica capaz de auxiliar o indivíduo a resgatar sua subjetividade e a ética da convivência, no âmbito coletivo (URIARTE, 2004).

Todavia, há também o texto de Hans-Thies Lehmann (2011), o qual, a despeito de aparentemente estar no mesmo circuito de crítica à noção de Indústria Cultural de Adorno, exibe proposições de outra ordem. $\mathrm{O}$ autor questiona os sentidos e rumos que o teatro infantojuvenil pode e deve tomar, propondo de maneira categórica um triplo abandono: da função didática do teatro, da superação do caráter doutrinário e do uso da arte para conscientizar. Apoiado na ideia de Walter Benjamim, para quem não é possível ensinar boas condutas senão dar exemplos, assim como na leitura 
histórica do teatro juvenil, o autor preconiza a retomada da arte como um jogo estético com um fim em si mesmo. Para isso, retoma Friedrich Schiller, em sua oposição à transformação do teatro num espaço de doutrinação e esclarecimento, didatismo moral e religioso, de sorte a sugerir, com base no autor, a noção de que apenas no livre jogo estético a beleza pode se tornar, de modo indireto, uma questão política, a qual transforma o indivíduo educado, nesse sentido lúdico, em alguém com um comportamento "[...] mais social e mais acertado possível." (LEHMANN, 2011, p.284). Nessa perspectiva, apesar da crítica, ao final, a arte teria uma função social de acertar o sujeito.

Em resumo, como proveniência para o processo de ensino da arte teríamos hoje a necessidade de humanizar, sensibilizar para o diferente e, principalmente, um enfoque maior no desenvolvimento das pessoas do que das artes, sendo este desenvolvimento do sujeito arte educativo alicerçado nas discussões sobre contexto/cotidiano.

\section{CONSIDERAÇÕES FINAIS}

As críticas extraídas do corpus desta pesquisa e aqui utilizadas oscilam entre dois extremos: críticas que visam à afirmação de um sujeito da arte-educação e críticas que quebram a necessidade de um sentido social ou educativo para a arte ou seu ensino.

$\mathrm{Na}$ primeira espécie, estão contidas a crítica à ideia de uma arte universal que entroniza a cultura de massa e o cotidiano, como forma de aproximação do aluno com o mundo da arte; a crítica à escolarização da formação, a qual enaltece a noção de comunidade no lugar da escola; a crítica a Adorno, por este não considerar a Indústria Cultural como cultura do aluno; e a crítica de Lehmann à função didática do teatro, da superação do caráter doutrinário e do uso da arte para conscientizar, mas que, ao final, promove um sujeito socialmente acertado. Ainda nessa posição estariam também as críticas à ideia de diferença como tolerância à diversidade e, em seu lugar, a exaltação e a busca de um processo de diferenciação no contato com o Outro.

Notamos que esses autores, a despeito de criticarem a visão de Adorno (1988), ainda se prendem ao cerne de sua teoria estética, segundo a qual, com a autonomia alcançada pela arte, no século XX, ela teria perdido sua justificativa social e, portanto, seu direito à existência. Esses autores, apesar de suas críticas ao suposto elitismo o qual pode advir da teoria frankfurtiana e ao seu combate a todos os aspectos da Indústria Cultural, não deixaram de lado o incômodo instilado por Adorno, ao diagnosticar a catastrófica existência de uma arte sem um sentido social, e passam a propor formas de arte que tenham uma justificativa de sua presença, no seio da sociedade.

No outro extremo, estão a crítica à noção de arte como instrumento de humanização; a resposta negativa a qualquer função social, emancipadora ou conscientizadora da arte; a crítica ao sensível como afirmação de uma forma já estabelecida na interioridade de um sujeito psicologizado; a tentativa de repor a arte como criadora de quadros de referências próprios ou criadora de mundos, para que o ser humano possa habitar; e, por fim, como possibilidade de ser um modo de pensamento.

Essas críticas são uma amostra da sofisticação em que se encontra a produção do sujeito das práticas artístico-pedagógicas hodiernas. A arte ou aquilo que, diante de tantas críticas feitas, já não podemos mais chamar de arte, mas de seus correlatos e derivados, é um mecanismo que melhor arregimenta, de maneira sempre indireta, consciente ou inconsciente, individualizada ou coletiva, as formas de ser e de produzir a existência nos nossos dias. Ao voltamos o olhar para o corpus analítico, fica patente em nossas análises que esse mecanismo se organizou em meio a um processo de pedagogização e de psicologização da vida.

Os textos de Icle e Farina destacam-se por serem os únicos que, em momento nenhum, vão se referir ao sujeito da arte ou da educação como um homem a ser humanizado ou que possua como referência primeira de mundo um si mesmo e sua interioridade. Apesar de trabalharmos com um estrato temporal mais reduzido, pudemos ver junto a Barbosa (1990/2008a) que essa noção já começava a se esboçar no Brasil, no período do Estado Novo, com o Canto Orfeônico como um projeto de Estado Nacional, em que a arte e as vicissitudes da estética deveriam ser utilizadas para compor o homem civilizado brasileiro.

Nossas análises indicam que, nesses setenta anos, ocorreram: primeiro, uma grande intensificação do sentido de liberdade do indivíduo; segundo, uma intensificação das questões de ordem 
pedagógica, com uma didatização da vida sem precedentes e, com ela, uma amortização e infantilização dos possíveis atos violentos da arte, a qual passa a ter uma aura inocente, na escola; e, terceiro, o espraiamento de um tipo específico de psicologismo, que visa a tornar o olhar e a cultura do sujeito gravitados em torno dele mesmo, de tal sorte que se tornam incomunicáveis aos outros. Esse psicologismo guarda a noção de multiculturalismo como diversidade e tolerância. Logo depois, com as críticas a essa noção de diferença como diversidade, sugere-se que esse sujeito deve jogar-se, imiscuir-se nas múltiplas identidades, deve tornar-se fluxo. Como assinala Loponte (2006, p.44), ao problematizar a pedagogização da arte diante da precariedade da formação docente, não se trata de produzir uma resolução completa dos problemas ou uma emancipação total, porém, uma “[...] diferença que [...] não cessa de se produzir [...] na invenção, criação estética de si mesmo.”. Isso permitiria a produção de um sujeito não sujeitado ao seu presente, à sua cultura ou território.

Todavia, para que isso fosse possível, ao longo do século XX, com grande intensificação entre as décadas de 1990 e a primeira década de 2000, foram oferecidas às práticas escolares alguns vórtices conceituais e práticos: a intensificação da visão platônica da arte com fins de desenvolvimento do cidadão e não da polis; a mudança no objetivo da arte, antes centrado nela mesma e agora voltada para o desenvolvimento das pessoas; a intencionalidade do ato pedagógico redirecionado ao contexto e ao cotidiano do aluno e não aos saberes universais da pedagogia; a crítica à escolarização; a negação do universalismo e do etnocentrismo europeu, em benefício do popular e do conhecimento local; a cultura de massa e a Indústria Cultural vistas como ponte entre o aluno e o conhecimento, e não mais como alvo a ser combatido. Nesse sentido, essas mudanças oferecidas paulatinamente à educação pela psicologia, pela pedagogia e pelo próprio mundo da arte - e aqui sintetizadas na proposta da ECV -, permitiram produzir o sujeito subjetivado em uma psicopedagogia da arte.

Entretanto, suspeitamos que conduzir a educação do sujeito por meio desse processo não traria sua emancipação como o homem que pode se conduzir, como querem quase todos os autores do corpus pesquisado, mas o coloca no centro do mecanismo de organização societária da nossa época. Ao estudamos apenas algumas das linhas que fazem parte da forja desse sujeito da ECV, ao verificar quais os efeitos de poder que implicam, observando suas materialidades, e ao descrever a parte da sua história ligada às problematizações da tríade arte/psicologia/educação, vimos que ele está absolutamente comprometido com os jogos de poder e passa a ser uma personagem central no processo de formação do sujeito empresário de si (COSTA, 2009), hoje essencial para o funcionamento do capitalismo.

Além disso, somos levados a ressaltar que essas práticas educativas da ECV acabam por produzir o consenso e a profusão de identidades, que sempre se assemelham ao que lhe é próprio, impedindo assim a realização da dimensão política da estética e da arte, no desarranjo das práticas identitárias e na ruptura dos modelos universais de igualdade, os quais tendem a manter o processo de dominação e subordinação (RANCIÈRE, 1996).

\section{REFERÊNCIAS}

ADORNO Theodor. Teoria Estética. Tradução de Artur Mourão. Lisboa: Edições 70, 1988.

AGAMBEN, Giorgio. O que um dispositivo? In: AGAMBEN, Giorgio. O que é o contemporâneo? e outros ensaios. Tradução de Vinicius Nicastro Honesko. Chapecó, SC: Argos, 2009, p.25-49

ANDRADE, Julia Pinheiro. Narrativas de nosso tempo: notas sobre a canção popular como experiência de formação. Educação em Revista, v. 25, n. 1, p. 15-36, abr. 2009.

ARROYO, Emilio Martinez; SANTOS, Bia. A participação como processo cognitivo: Reflexões a partir da Exposição Cidades Interativas. Revista Porto Arte, Porto Alegre, v. 16, n. 26, p. 08-10, maio 2009.

ARROYO, Margarete. Um olhar antropológico sobre práticas de ensino e aprendizagem musical. Revista da $A B E M$, n. 5, p.13-20, set. 2000. 
BARBOSA, Ana Mae. Ensino da arte: memória e história. São Paulo: Perspectiva, 2008. (Obra originalmente publicada em 1990).

BARBOSA, Ana Mae; PARDO, Mercedes Frígola. Arte na educação: interterritorialidade, interdisciplinaridade e outros inter. Visualidades: Revista do Programa de Mestrado em Cultura Visual. Goiânia, v. 3, n. 1, p.38-9, jun./jul. 2005.

BERTONI, Luci Mara. Arte, Indústria Cultural e Educação. Cadernos Cedes, n. 54, p.76-81, ago. 2001.

BRANDÃO, Carlos Antônio Leite. Educação, arte e política: reflexões sobre o Sofista, o Político e a República de Platão. Educação em Revista, n. 33, p. 49-66. jun. 2001.

BRANDÃO, Carlos Antônio Leite. Vocação de criar: Anotações sobre a cultura e as culturas populares. Cadernos de pesquisa, v.39, n.138, p.715-746, set./dez.2009.

BRITO, Teca Alencar de. Ferramentas com brinquedos: a caixa da música. Revista da ABEM, Porto Alegre, v. 24, p. 89-93, set. 2010.

BRITO, Teca Alencar de. FLADEM - Fórum Latinoamericano de Educação Musical: Por uma Educação Musical Latinoamericana. Revista da ABEM, Londrina, v.20, n.28, p.105-117, 2012.

CABRAL, Biange. O professor-artista: perspectivas teóricas e deslocamentos históricos. Urdimento. Florianópolis. v. 1, n.10, p. 35-44, dez. 2008.

CASTILHO, Eleide Gonçalves. O ensino de música no contexto escolar. ETD: Educação Temática Digital, v. 2, n. 2, p. 181-192, 2001.

COELHO, Roseane Martins. Novos tempos pedem novas narrativas na educação das artes visuais. Visualidades: Revista do Programa de Mestrado em Cultura Visual. Goiânia, v. 8, n. 1, p. 207-217, jan./jun. 2010.

COSTA, Sylvio de Sousa Gadelha. Biopolítica, governamentalidade e educação: introdução e conexões, a partir de Michel Foucault. Belo Horizonte: Autêntica, 2009.

CRUZEIRO, Cristina Pratas. Práticas de sociabilidade na arte contemporânea. Visualidades: Revista do Programa de Mestrado em Cultura Visual. Goiânia, v. 8, n. 1 p. 25-37, jan./jun. 2010.

CUNHA, Marcus Vinicius; SOUZA, Aline Vieira. Cecília Meireles e o temário da escola nova. Cadernos de Pesquisa. v. 41, n. 144, p. 850-865, set./dez. 2011.

DELEUZE, Gilles. Niețşche e a Filosofia. Tradução, Mariana de Toledo Barbosa, Ovídio de abreu Filho. São Paulo: n-1, 2018

DESGRANGES, Flávio. Mediação Teatral: anotações sobre o Projeto Formação de Público. Urdimento, n.10, p. 75-83, dez. 2008.

DIAS, Belidson. Acoitamentos: locais da sexualidade e gênero na arte/educação contemporânea. Visualidades: Revista do Programa de Mestrado em Cultura Visual da Faculdade de Artes Visuais/UFG. Goiânia, v. 4, n. 1 e 2, p. 101-131, 2006.

FABIANO, Luiz Hermenegildo. Adorno, arte e educação: negócio da arte como negação. Educação $e$ Sociedade, Campinas, v. 24, n. 83, p. 495-505, ago. 2003.

FANTIN, Monica. Cinema e imaginário infantil: a mediação entre o visível e o invisível. Educação e Realidade, v. 34, n. 2, p. 205-223, maio/ago. 2009. 
FARINA, Cynthia. Mutações do sensível. A arte deslocalizada e o corpo desincorporado. Porto Arte. Porto Alegre, v. 18, n. 30, maio 2011.

FERRARO, Rosângela Mara. Procura-se um Lugar para a Arte Contemporânea no Currículo Escolar. Pro-Posições, Campinas, v. 10, n. 3 (30), p. 76-83, nov.1999.

FERREIRA, Francisco Romão. Ciência e arte: investigações sobre identidades, diferenças e diálogos. Educação e Pesquisa, São Paulo, v. 36, n. 1, p. 261-280, jan./abr. 2010.

FOUCAULT, Michel. Nietzsche, a genealogia e a história. In: FOUCAULT, Michel. Microfísica do poder. Tradução de Roberto Machado. Rio de Janeiro: Graal, 1979.

FOUCAULT, Michel. O que é a Crítica? (Crítica e Aufklärung). Tradução de C. Galdino. In: FOUCAULT, Michel. Estratégias, poder-saber. Rio de Janeiro: Forense Universitária, 2003 (Ditos e Escritos, $\mathrm{VI})$.

FOUCAULT, Michel. Arqueologia do saber. Tradução de Luiz Felipe Baeta Neves. 7. ed. Rio de Janeiro: Forense Universitária, 2008.

FOUCAULT, Michel. Vigiar e punir. nascimento da prisão. Tradução de Raquel Ramalhete. 41. ed. Petrópolis: Vozes, 2013.

FOUCAULT, Michel. M .Sobre a genealogia da Ética: um Resumo do Trabalho em Curso. In: FOUCAULT, Michel. Genealogia da Ética, Subjetividade e Sexualidade. Rio de Janeiro: Forense Universitária, 2014. (Ditos e Escritos, IX).

FRAYZE-PEREIRA, João A. A dimensão estética da experiência do outro. Pro-Posições. Campinas, v. 15, n. 1 (43), p. 19-25, jan./abr. 2004.

GALIZIA, Fernando Stanzione. Educação musical nas escolas de ensino fundamental e médio: considerando as vivências musicais dos alunos e as tecnologias digitais. Revista da $A B E M$, Porto Alegre, v. 21, p.76-83, mar. 2009.

GOLDEMBERG, Ricardo. Educação Musical: A Experiência do Canto Orfeônico no Brasil. Pro-Posições. v. 6, n. 3 (18), p.103-109, nov. 1995.

GUIMARÃES, Leda. Variações em torno dos jogos estéticos, artísticos e pedagógicos no ensino "superior" de artes visuais. Visualidades: Revista do Programa de Mestrado em Cultura Visual. Goiânia, v. 3, n. 1, jun./jul. 2005.

HERMANN, Nadja. Ética: a aprendizagem da arte de viver. Educação e Sociedade. v. 29, n. 102, p. 15-32. jan./abr. 2008.

ICLE, Gilberto. Da Pedagogia do Ator à Pedagogia Teatral: verdade, urgência, movimento. O Percevejo, v. 1, n. 2 p.1-9 jul./dez. 2009.

JOLY, Maria Carolina Leme; JOLY, Ilza Zenker Leme. Práticas musicais coletivas: um olhar para a convivência em uma orquestra comunitária. Revista da ABEM. Londrina v. 19, n. 26, p. 79-91, jul./dez.2011.

KATER, Carlos. O que podemos esperar da educação musical em projetos de ação social. Revista da ABEM. Porto Alegre, v. 10, p. 43-51, mar. 2004.

KEBACH, Patrícia; DUARTE, Rosangela; LEONINI, Márcio. Ampliação das concepções musicais nas recriações em grupo. Revista da ABEM. Porto Alegre, v. 24, p. 64-72, set. 2010. 
LAZZARIN, Luís Fernando. Por uma Crítica à Nova Filosofia da Educação Musical. Educação e Realidade, v. 30, n. 1, p. 103-124. jan./jun. 2005.

LAZZARIN, Luís Fernando. Grafite e o Ensino da Arte. Educaşão e Realidade, v. 32, n. 7, p. 59-74. jan./jun. 2007.

LAZZARIN, Luís Fernando. Multiculturalismo e multiculturalidade: recorrências discursivas na educação musical. Revista da ABEM. Porto Alegre, v. 19, 121-128, mar. 2008.

LEHMANN, Hans-Thies. Das Crianças, do Teatro, do Não-compreender. Revista Brasileira de Estudos da Presença, v. 1, n. 2, p. 268-285, jul./dez. 2011.

LIMA, Maria Stela Beraldo. Avaliando Artes. Educação Temática Digital, Campinas, v. 7, n. esp., p. $117-$ 126, jun. 2006.

LOPONTE, Luciana Gruppelli. Gênero, educação e docência nas artes visuais Educação e Realidade, v. 30, n. 2, p. 243-259, jul./dez. 2005.

LOPONTE, Luciana Gruppelli. Docência Artista: arte, gênero e ético-estética docente. Educaşão em Revista, n. 43, p. 35-56, 2006.

LOPONTE, Luciana Gruppelli. Arte e metáforas contemporâneas para pensar infância e educação. Revista Brasileira de Educação. v. 13, n. 37, p. 112-122, jan./abr. 2008.

LOUREIRO, Robson. Considerações Sobre a Filosofia de Theodor Adorno e o Pós-Moderno. Educação \& Realidade, v. 34, n. 1, p. 175-190, jan./abr. 2009.

MARQUES, Isabel. Artista às avessas a ação cultural em diálogo com a educação. Sala Preta, v. 12, n. 1, p. 24-35, jun. 2012.

MARTINS, Raimundo. Por que e como falamos da cultura visual? Visualidades: Revista do Programa de Mestrado em Cultura Visual, v. 4, n. 1 e 2, 2006.

MARTINS, Raimundo; TOURINHO, Irene. Entre contingências e experiências vividas... Propostas para pensar um ensino crítico em artes visuais. Visualidades: Revista do Programa de Mestrado em Cultura Visual. Goiânia, v. 3, n. 1, p. 86-111, 2005.

MORAES, Abel. Multifrenia na educação musical: diversidade de abordagens pedagógicas e possibilidades para as profissões da música. Revista da ABEM. Porto Alegre, v. 13, 55-64, mar. 2006.

NEVES, Cynthia Agra de Brito. Da poesia visual concreta à poesia virtual concreta: a ciberliteratura na sala de aula. Educação Temática Digital, v. 12, n. 01, p. 124-146, jul./dez. 2010.

NIETZSCHE, Friedrich. O nascimento da tragédia, ou Helenismo e pessimismo. Tradução, notas e posfácio de J. Guinsburg. São Paulo: Companhia das Letras, 1992.

NIETZSCHE, F. Assim Falou Zaratustra. Tradução, notas e posfácio de Paulo César de Souza. São Paulo, Companhia das Letras, 2011.

OLIVEIRA, Débora Alves. Musicalização na educação infantil. Educação Temática Digital. Campinas, v. 3, n. 1, p. 98-108, dez. 2001.

OSTETTO, Luciana. Na dança e na educação: o círculo como princípio. Educaşão e Pesquisa. São Paulo, v. 35, n. 1, p. 177-193, jan./abr. 2009. 
OSTETTO, Luciana. Para encantar, é preciso encantar-se: danças circulares na formação de professores. Cadernos CEDES, v. 30, n. 80, p. 40-55, jan./abr. 2010.

PAIS, José Machado. Artes de Musicar e de improvisar na cultura popular. Cadernos de Pesquisas, v. 39, n. 138, p. 747-773, 2009.

PENNA, Maura. Professores de música nas escolas públicas de ensino fundamental e médio uma ausência significativa. Revista da ABEM. Porto Alegre, v. 7, p. 7-19, set. 2002.

PENNA, Maura. Poéticas musicais e práticas sociais: reflexões sobre a educação musical diante da diversidade. Revista da ABEM, Porto Alegre, v. 13, p. 7-16, set. 2005.

PENNA, Maura. Desafios para a educação musical: ultrapassar oposições e promover o diálogo. Revista da ABEM. Porto Alegre, v.13, n. 14, p. 35-43, mar. 2006.

PENNA, Maura. Mr. Holland, o professor de música na educação básica e sua formação. Revista da $A B E M$, Porto Alegre, v. 23, p. 25-33, mar. 2010.

PEREIRA, Marcelo Andrade. Pedagogia da Performance: do uso poético da palavra na prática educativa. Educação e Realidade, v. 35, n. 2, p. 139-156 maio/ago. 2010.

PINEAU, Elyse Lamm. Nos Cruzamentos entre a Performance e a Pedagogia: uma revisão prospectiva. Educação e Realidade, v. 35, n. 2, p. 89-114, maio/ago. 2010.

PUPO, Maria Lúcia de Souza Barros. Dentro ou fora da escola? Urdimento, n. 10, p. 55-60, dez. 2008.

PUPO, Maria Lúcia de Souza Barros. Em cena: mutações e desafios. O Percevejo, v. 1, n. 2, p. 3-7, jul./dez. 2009

PUPO, Maria Lúcia de Souza Barros. Alteridade em cena. Sala Preta, v. 12, n. 1, p. 46-57, jun. 2012.

RANCIÈRE, Jacques. O Desentendimento - política e filosofia. Tradução: Ângela Leite Lopes. São Paulo: Editora 34, 1996.

RIBAS, Maria Guiomar de Carvalho. Práticas musicais na Educação de Jovens e Adultos: uma abordagem geracional. Revista da ABEM. Porto Alegre, v. 21, p. 124-134, mar. 2009.

RICHTER, Sandra Regina Simonis. O sensível sob o admirar filosófico. Educação \& Realidade, v. 30, n. 2, p. 187- 202, jul./dez. 2005.

RODRIGO, Lídia Maria. Platão contra as pretensões educativas da poesia homérica. Educação e Sociedade, v. 27, n. 95, p. 523-539, maio/ago. 2006.

RODRIGUES, Gabriela de Andrade. Pedagogias queer e libertária para educação em cultura visual. Educação e Pesquisa. São Paulo, v. 36, n. 3, p. 735-745, set./dez. 2010.

RUSSELL, Joan. Perspectivas socioculturais na pesquisa em educação musical: experiência, interpretação e prática. Revista da ABEM. Porto Alegre, v. 14, p. 7-16, mar. 2006.

SANTOS, Vera Lúcia Bertoni. Contadores de Histórias sobre Teatro e Educação. Revista Brasileira de Estudos da Presença. Porto Alegre, v. 1, n. 1, p. 189-213, jan./jun. 2011.

SEBBEN, Egon Eduardo; SUBTIL, Maria José. Concepções de adolescentes de $8^{a}$ série sobre música: possíveis implicações para a implementação das práticas musicais na escola. Revista da ABEM. Porto Alegre, v. 23, p. 48-57, mar. 2010. 
SHAPIRO, Sherry. Em direção a professores transformadores: perspectivas crítica e feminista para o ensino da dança. Pro-Posições, v. 9, n. 2 (26), p. 35-45, jun. 1998.

SILVA, Igor de Almeida. A criança e o sótão. Sala Preta, v. 12, n. 1, p. 58-68, jun. 2012.

SILVEIRA, Alessandro Frederico da; ATAIDE, Ana Raquel Pereira; FREIRE, Morgana Lígia de Farias. Atividades lúdicas no ensino de ciências: uma adaptação metodológica através do teatro para comunicar a ciência a todos. Educar em Revista. Curitiba, n. 34, p. 251-262, 2009.

SITTA, Marli S. C.; ORMEZZANO Graciela; POTRICH, Cilene M. Teatro na escola: Espaciotempo do pensamento e da Sensibilidade. Urdimento, n. 7 p. 157-166, dez. 2005.

STINSON, Susan. Uma Pedagogia Feminista para Dança da Criança. Pro-Posições, v. 6 n. 3 (18), p. 77-89, nov. 1995.

TROJAN, Rose Meri. Arte e a humanização do homem: afinal de contas, para que serve a arte? Educar em Revista. Curitiba, n. 12, p. 87-96, 1996.

URIARTE, M. Z. Música e escola: um diálogo com a diversidade. Educar em Revista. Curitiba, n. 24, p. 245-258, 2004.

VICTORIO FILHO, Aldo. Estéticas nômades: outras histórias, outras estéticas, outros... ou o funk carioca: produção estética, epistemológica e acontecimento. Visualidades: Revista do Programa de Mestrado em Cultura Visual. Goiânia, v. 6, n. 1 e 2, abr. 2012.

VITELLI, Celso. Adolescências e identidades estéticas no cotidiano. Educação em Revista. Belo Horizonte, v. 25, n. 03, p.43-74, dez. 2009.

WAZLAWICK, Patrícia; MAHEIRIE, Kátia. Sujeitos e músicas em movimentos criadores compondo comunidades de prática musical. Revista da ABEM. Porto Alegre, v. 21, p. 103-112, mar. 2009. 